\title{
Localizing an occult gastrointestinal bleeding by wireless PillCam SB capsule videoendoscopy in a patient with the HeartMate II left ventricular assist device
}

\author{
J. F. Matthias Bechtel, MD, ${ }^{\mathrm{a}}$ Peter Wellhöner, MD, ${ }^{\mathrm{b}}$ Efstratios I. Charitos, MD, ${ }^{\mathrm{a}}$ Bence Bucsky, MD, ${ }^{\mathrm{a}}$ \\ Michiel Morshuis, MD, ${ }^{c}$ and Hans H. Sievers, MD, ${ }^{a}$ Lübeck and Bad Öeynhausen, Germany
}

Gastrointestinal bleeding is a known problem in patients with left ventricular assist devices (LVADs). The exact source of the bleeding is sometimes difficult to ascertain. In gastroenterology, wireless capsule videoendoscopy has become an important diagnostic tool, especially when the small intestine is involved. It is not known, however, whether an implanted LVAD would interfere with signal transmission from the capsule, nor whether the signals from the capsule would cause malfunction of the LVAD. We report the case of a patient in whom significant gastrointestinal bleeding developed after implantation of a HeartMate II LVAD (Thoratec Corporation, Pleasanton, Calif). The source of the bleeding was successfully identified by wireless PillCam SB capsule videoendoscopy (Given Imaging Ltd, Yoqneam, Israel).

\section{CLINICAL SUMMARY}

A 70-year-old man had a massive myocardial infarction caused by occlusion of the left main coronary artery. Emergency coronary artery bypass grafting was undertaken. Shock was treated initially with a paracorporal centrifugal pump (Centrimag; Levitronix LLC, Waltham, Mass) and later with an intra-aortic balloon pump. The patient continued to require inotropic support and did not tolerate even the lightest exertion. Because the patient had no neurologic deficits or other known illnesses, we decided that he was a suitable candidate for long-term support. Eleven days after the myocardial infarction, implantation of a HeartMate II LVAD was performed in a routine manner. The postopera-

\footnotetext{
From the Departments for Cardiac and Thoracic Vascular Surgery ${ }^{\mathrm{a}}$ and Internal Medicine, Division I, ${ }^{\mathrm{b}}$ University of Lübeck, Lübeck, Germany, and the Department of Thoracic and Cardiovascular Surgery, Heart and Diabetes Center, North Rhine Westphalia/University Hospital of Bochum, ${ }^{\mathrm{c}}$ Bad Öeynhausen, Germany. Disclosures: Dr. Michiel Morshuis reports consulting fees from Thoratec.

Wireless PillCam SB capsule videoendoscopy is manufactured by Given Imaging Ltd, Yoqneam, Israel. HeartMate II left ventricular assist device is manufactured by Thoratec Corporation, Pleasanton, Calif.

Received for publication Aug 13, 2008; accepted for publication Aug 16, 2008; available ahead of print May 18, 2009.

Address for reprints: J. F. Matthias Bechtel, MD, University of Lübeck, Department for Cardiac Surgery, Ratzeburger Allee 160, 23538, Lübeck, Germany (E-mail: m.bechtel@herzchirurgie-luebeck.de).

J Thorac Cardiovasc Surg 2010;139:e73-4

$0022-5223 / \$ 36.00$

Copyright $\subset 2010$ by The American Association for Thoracic Surgery doi: $10.1016 / j$.jtcvs.2008.08.073
}

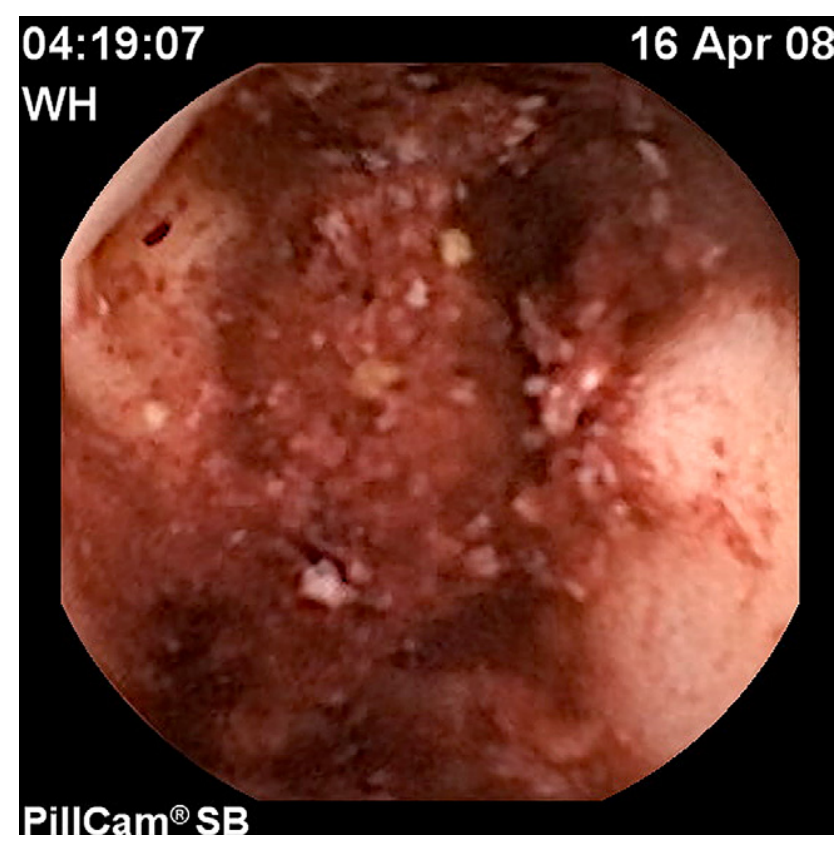

FIGURE 1. Image taken with PillCam videocapsule endoscopy showing diffuse bleeding in cecum without identifiable source. Preceding images of terminal ileum and ileocecal valve were without signs of blood.

tive course was largely uneventful, and the patient was discharged home. For anticoagulation, phenprocoumon (target international normalized ratio of 2.5) and clopidogrel (75 mg every second day) were given.

Five months after implantation, the patient reported occasional dark and foul-smelling defecations. Guaiac-based fecal testing confirmed the presence of blood. Esophagogastroduodenoscopy revealed no pathologic findings. Clopidogrel was discontinued. The patient felt well and went home again. During the next weeks, however, the frequency of melena increased and the hemoglobin concentration decreased. Colonoscopy was performed but revealed no pathologic findings. The patient was again discharged home, and the target international normalized ratio was lowered to 2.0. Melena persisted, however, and the hemoglobin concentration decreased to $72 \mathrm{~g} / \mathrm{L}$. The patient was hospitalized and underwent transfusion with 3 units of packed red blood cells. Inspection of the feces showed signs of fresh blood. There were no hemorrhoids. Another colonoscopy was performed; 


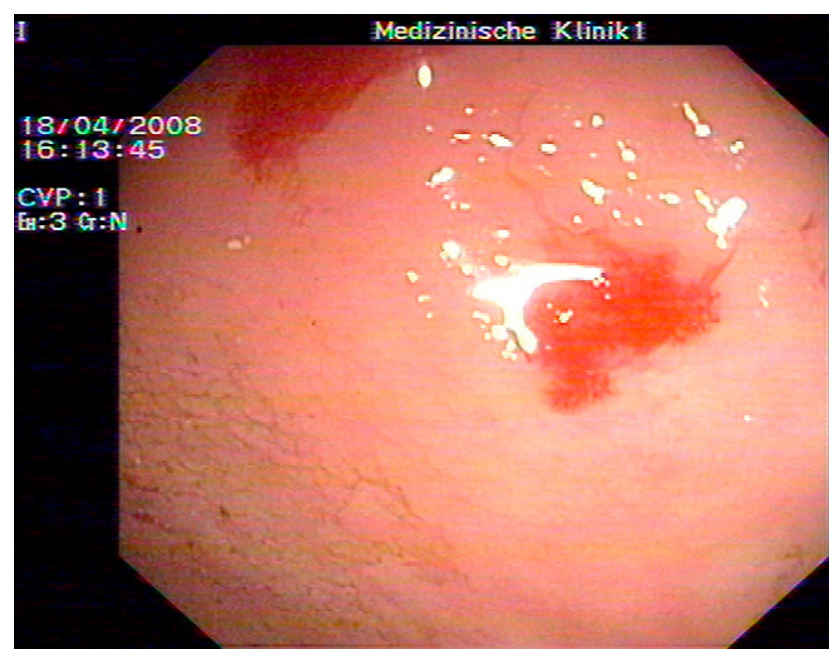

FIGURE 2. Image taken with conventional colonoscopy showing angiodysplasia in cecum with minimal bleeding signs.

again, however, the source of the bleeding could not be identified. Bleeding from the small intestine thus appeared to be most likely. After conventional preparation, wireless capsule videoendoscopy was performed with the PillCam SB. The capsule consists of a small digital camera that takes 2 images per second. These images are sent to an external receiver through wireless technology. There were neither problems with capsule passage through the gastrointestinal tract nor with signal transmission, and no malfunction of the HeartMate II occurred. Analysis of the data captured revealed blood in the cecum (Figure 1) but not proximal to it in the small intestine. Another colonoscopy was performed, and two small angiodysplasias were found in the cecum (Figure 2) and successfully treated with argon plasma coagulation and clipping. The patient was discharged home the day after the procedure.

\section{DISCUSSION}

Gastrointestinal bleeding is a known problem in patients with LVADs, and its occurrence is promoted by the multiple morbidities present in the supported patients and the need for oral anticoagulation, usually in conjunction with antiplatelet therapy. In addition, LVADs may cause an acquired von Willebrand disease, ${ }^{1}$ resembling Heyde syndrome in aortic stenosis, ${ }^{2}$ which is characterized by bleeding from gastrointestinal angiodysplasias. These vascular malformations may be located anywhere in the gastrointestinal tract, ${ }^{3}$ and it thus may be necessary to scan the small intestine for bleeding. In this regard, wireless capsule videoendoscopy has become an important diagnostic tool. There has only been a single report in the literature on capsule endoscopy in patients with LVADs, ${ }^{4}$ however, and that small report did not specify the endoscopy system used. The concern arises that wireless signal transmission from the capsule might be disturbed by the electromagnetic field of the LVAD. Such considerations are not totally speculative in light of reported adverse interactions between the HeartMate II and a specific type of implantable cardioverter-defibrillator. ${ }^{5}$

In retrospect, wireless capsule videoendoscopy may not have been necessary in our case. Two previous had not identified the source of bleeding, however, probably because of its intermittent nature. Wireless capsule videoendoscopy was of great help in finding and treating the bleeding. No interactions between the HeartMate II and the PillCam SB were observed.

\section{References}

1. Geisen U, Heilmann C, Beyersdorf F, Benk C, Berchtold-Herz M, Schlensak C, et al. Non-surgical bleeding in patients with ventricular assist devices could be explained by acquired von Willebrand disease. Eur J Cardiothorac Surg. 2008;33: 679-84.

2. Vincentelli A, Susen S, Le Tourneau T, Six I, Fabre O, Juthier F, et al. Acquired von Willebrand syndrome in aortic stenosis. N Engl J Med. 2003;349: 343-9.

3. Henne S, Denzer U, Seitz U, Gottsche J, Soehendra N, Lohse A. Recurrent gastrointestinal bleeding and aortic valve stenosis (Heyde syndrome): need for valve replacement? [article in German]. Z Gastroenterol. 2007;45:245-9.

4. Daas AY, Small MB, Pinkas H, Brady PG. Safety of conventional and wireless capsule endoscopy in patients supported with nonpulsatile axial flow Heart-Mate II left ventricular assist device. Gastrointest Endosc. 2008;68:379-82.

5. Matthews JC, Betley D, Morady F, Pelosi F Jr. Adverse interaction between a left ventricular assist device and an implantable cardioverter defibrillator. J Cardiovasc Electrophysiol. 2007;18:1107-8. 